Jiming WANG, Jie LIU, Anlin SHAO, Lixin TANG

\title{
Special issue: Operations analytics and optimization for manufacturing, logistics and energy systems
}

(C) The Author(s) 2017. Published by Higher Education Press. This is an open access article under the CC BY license (http:// creativecommons.org/licenses/by/4.0)

Practical manufacturing, logistics and energy systems are confronted with the problems of high energy consumption, tremendous production and logistics costs, and excessive resource consumption. To meet these challenges, operations analytics and optimization for smart industry is proposed to realize system optimization management through the integration and innovation of industrial management theory, engineering technology and management mode, so as to improve the engineering management level of manufacturing, logistics and energy systems.

Revolving around the practical requirements and developing trend of engineering management in the new era, this special issue investigates state-of-the-art scientific and technological problems in operations analytics and optimization for smart industry, and explores how to conduct the description, diagnosis, and forecast of the production and logistics process accurately through data analytics by employing Cyber-physics System (CPS) so as to optimize the decision making in production planning, scheduling and operation to realize smart industry. The scope of this special issue covers planning and scheduling for manufacturing, energy, and logistics systems; application of industrial CPS; monitoring, diagnosis, traceability and operation optimization for production process; green and security engineering management in manufacturing systems; optimization for smart energy systems and logistics systems. The special issue includes 12 excellent contributions, focusing on operations analytics and optimization for manufacturing, logistics, and energy systems, covering methods and solutions for a wide range of challenges.

Operations analytics and optimization for manufacturing systems is considered as the core of "Industry 4.0" and "Made in China 2025." Wang introduces the petrochemical CPS and provides theoretical support and implementation reference of CPS by investigating the construction practice of multilevel CPS in China Petrochemical Corporation. Brunaud and Grossmann propose a network representation for the multilevel decision structure of supply chains and analyze the components involved in finding integrated solutions, which maximize the sum of the benefits of all nodes in decision network. Chen presents a survey of key properties of $L^{\natural}$-convexity and illustrates the techniques of applying $L^{\natural}$-convexity through a detailed analysis of several inventory models. Zhang reviews the methodologies of analyzing stochastic manufacturing and service system to aid practitioners in designing optimal policies for improving system performance. Joly and Miyake discuss the key lessons learned from an enterprisewide program devoted to developing and implementing an advanced refinery production scheduling technology. Wang et al. provide a novel sample average approximation method for solving a typical long-term strategic decision problem on supply chain network design, considering uncertain demands based on real big data from manufacturing systems. Li et al. develop a new effective and economical process monitoring method based on differential evolution to analyze the four main faults of the crude terephthalic acid hydropurification process. Wu et al. first apply a process hazard analysis method in investigating the hazards and operability in biofuel production. Shi et al. address a two-

Received September 11, 2017 
stage scheduling on a batch machine followed by a single machine and propose lower bounds and algorithms with theoretical analysis.

The logistics systems aim to realize the spatial transfer process of materials over time. In the logistics systems, it is of great importance to improve the customer service level and reduce the in-process inventory and logistics operation cost. These objectives can be achieved by making scientific decisions and optimizing the scheduling scheme. Zhou et al. propose a time-distance-based cost function for the China Railway Express, which provides alternative shipping route and transportation modes from Asia to Europe. Their study creates new opportunities for multimodal and intermodal transportation in the shipping industry, and provides many useful insights to various parties, such as business owners, the government, and the shipping industry.

China is confronted with serious shortage of energy resources. The 13th Five-Year Plan asserts that the Chinese government will strengthen the reduction of energy consumption, and support the development of low carbon industry and new/renewable energy. Huang et al. review the current research on system resilience enhancement and elaborate on resilience definition, as well as resilience quantification; they discuss several challenges and opportunities for system resilience enhancement. Zhang et al. formulate the distributed global utility maximization problems in the power grid as a series of sliding-window games by treating each building of energy consumer as a player, the global utility is decomposed to each player's payoff, and each game is played over a prediction horizon.

As two featured topics of this special issue, Hu et al. introduce the innovative engineering management works in discovery, development and construction of Sulige Gas Field super project. Shao comments on the challenges in industrial transformation through industrial intelligence, and provides the detailed solutions for mining enterprises.

Thus, we would like to express our sincere gratitude to all the contributors for their outstanding work and the reviewers for providing expert reviews to improve the quality of the submitted papers. We are also grateful to the Chinese Academy of Engineering for providing generous support and guidance.

\author{
Guest Editor-in-Chief \\ Jiming WANG \\ China Petrochemical Corporation, SINOPEC, China \\ E-mail: liujun@sinopec.com \\ Jie LIU \\ Shanghai University, China \\ E-mail: liuj@cae.cn \\ Anlin SHAO \\ ANSTEEL Group, China \\ E-mail: alshao@163.com \\ Lixin TANG \\ Northeastern University, China. \\ E-mail: lixintang@ise.neu.edu.cn
}

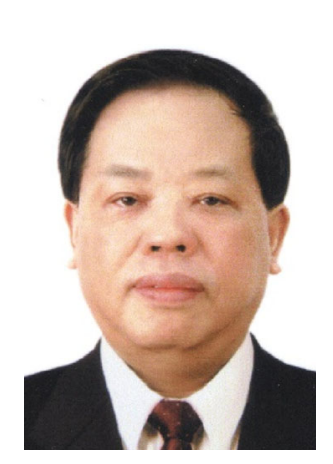

Jiming WANG is an academician at the Chinese academy of Engineering and an expert in oil refinement, petrochemical engineering, and engineering management. $\mathrm{He}$ is the director of the Process Systems Engineering Committee, which is affiliated to Systems Engineering Society of China, and the president of the China Business Council for Sustainable Development. He has served successively as Chairman and General Manager of Shanghai Petrochemical Company Limited, the Deputy General Manager of SINOPEC and the president of SINOPEC. In the long-term petrochemical engineering construction practice, he has put forward management theory and method suitable for China's refining chemical engineering construction for long-term petrochemical engineering construction practice. $\mathrm{He}$ also promoted the localization of technology and equipment and applied technologies with dependent intellectual property rights to world-class petrochemical engineering. He directed the construction of 300,000-tons-per-year ethylene project of Shanghai Petrochemical Company, accomplished the first and second ethylene and refinery renovation projects of SINOPEC, and completed the largest domestic single-series oil refining and contemporary world-class ethylene projects with the shortest time and the most economical investment. 


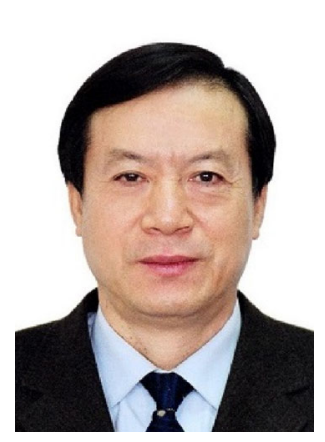

Jie LIU is an academician at the Chinese academy of Engineering and an expert on metallurgical automation and engineering management. Liu is a professor-level senior engineer and national-level expert with prominent contributions. He has been long engaged in the research and development of computer control system and mathematical model in metallurgical industry, focusing on the technological reformation of metallurgical plants, innovation, and practice in domesticating major metallurgical equipment. During his service in Wuhan Iron and Steel Corporation, a series of key projects led and executed by him were awarded the top grade, and first, second, and third prizes in the National Science and Technology Progress Award. During his service in ANSTEEL (Anshan Iron and Steel Group Corporation), he was awarded with "Ho Leung Ho Lee Foundation" Technology Science Award, the gold prize at the 2nd Yuan Baohua Enterprise Management Award, and the topgrade prize in metallurgical science and technology, successively. As the chief project director, Liu has accomplished China's first 1.7-m continuous casting and rolling line for thin slab, as well as China's first large-scale 1.78-m cold rolling production line for wide coil, which were awarded the first and second prizes at the National Science and Technology Progress Award, respectively. Moreover, the project "technological reformation and extension of ANSTEEL," which he directed, was honored as one of "a hundred major magnificent construction projects in the past 60 years since the founding of China."

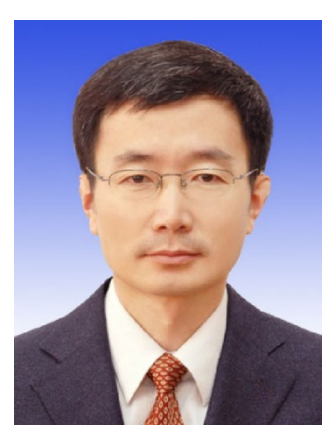

Anlin SHAO is an academician at the Chinese Academy of Engineering and an expert on mining and metallurgical engineering. He is the deputy general manager of ANSTEEL Group, the chairman of ANSTEEL Mining Group, the president of China Metallurgical and Mining Enterprises Association, and the director of the Technical Committee of National Iron Ore Standardization. He has been long-term engaged in lean iron ore technology development and project management. Shao presided over key techniques to overcome the bottlenecks of lean iron ore development and provided technical support for vitalizing iron ore resources in China. He applied system engineering theory to the practice of lean iron ore development project, created the "coordination of five stages" mining and metallurgy systems engineering mode, and introduced a systematic and innovative road for the green and efficient development of iron ore. He took the lead in compiling the first medium and long-term developmental plan for iron ore industry in China and chairs the establishment of multiple national and industrial criteria, which promoted the technological progress and sustainable development of metallurgical and mining. He has been awarded 3 second prizes of National Prize for Progress in Science and Technology, 1 top grade and 10 first prizes of science and technology at provincial level.

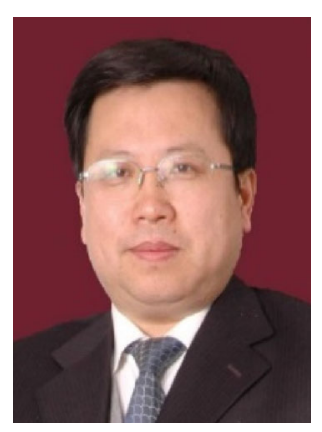

Lixin TANG is a Cheung Kong Scholars Chair Professor, the vice president of North eastern University and the director of the Institute of Industrial and Systems Engineering at Northeastern University of China. His research interests include engineering management of manufacturing system, particularly focusing on batching and scheduling of the production operations, logistics planning and scheduling, integer programming, and combinatorial optimization. As the principal investigator, he has implemented various practical engineering management projects on production and logistics scheduling for the steel manufacturing system. He has published 67 papers in international journals, such as Operations Research, Manufacturing \& Service Operations Management, IIE Transactions, and IEEE Transactions on Evolutionary Computation. The paper published on IIE Transactions (a flagship journal in the research area of industrial \& systems engineering, now renamed as IISE Transactions) won Design \& Manufacturing Best Application Paper Award. Prof. TANG also serves as associate editors for 7 international flagship and famous journals including IISE Transactions, IEEE Transactions on Evolutionary Computation, Journal of Scheduling, International Journal of Production Research, and Journal of the Operational Research Society, etc. 